\title{
A PROPOSED MODEL FOR OPTIMIZING THE DRAWBAR PULL FOR OFF-ROAD VEHICLES
}

\author{
Mohamed Khalil ${ }^{1}$, Mohamed Ali Emam ${ }^{2}$
}

UDC:629.1.05

\section{INTRODUCTION}

The study of the terra-mechanics is the interaction of tyres on various deformable terrains and it is not an easy task. The ideal vehicle has to provide excellent off-road capability with low fuel consumption, offer a high customizability for each specific mission and, last but not least, it has to be easy to operate. To meet these demands must be doing many of the research for the study of factors affecting these demands. The fuel economy has always been an important consideration for truck owners and fuel expenditure is one of the leading operating costs in the trucking industry.

Today, fuel economy is even more important with record high diesel prices. Many researchers are currently developing various technologies for improving fuel economy, such as; vehicle body aerodynamics, route management, engine and drive system and running gear design, and proper maintenance. Figure 1 represents the main factors that affect fuel economy during operating the vehicles in the real world.

One of the factors that have a considerable influence on vehicle fuel economy is the tyre inflation pressure as shown in the Figure 1. Therefore, this study focuses on the relationships between tyre slip, inflation pressure, and traction that when optimized the offroad vehicles` fuel consumption would be effectively reduced [1]. From the Figure 1, it could be said that the tyre inflation pressure is the one of the parameters that has affected the fuel economy during driving the vehicle and it can be used in a control system. This parameter affects the tyre slip, rolling resistance, drawbar pull, and traction force and fuel economy.

\footnotetext{
${ }^{1}$ Mohamed Khalil, Assoc. prof., Helwan University, Automotive and Tractor Engineering Dept., Faculty of Engineering - Mataria, Egypt, mohamedibrahim71@yahoo.com

${ }^{2}$ Mohamed Ali Emam, Helwan University, Automotive and Tractor Engineering Dept., Faculty of Engineering - Mataria, Egypt, mohemam_70@yahoo.com
} 


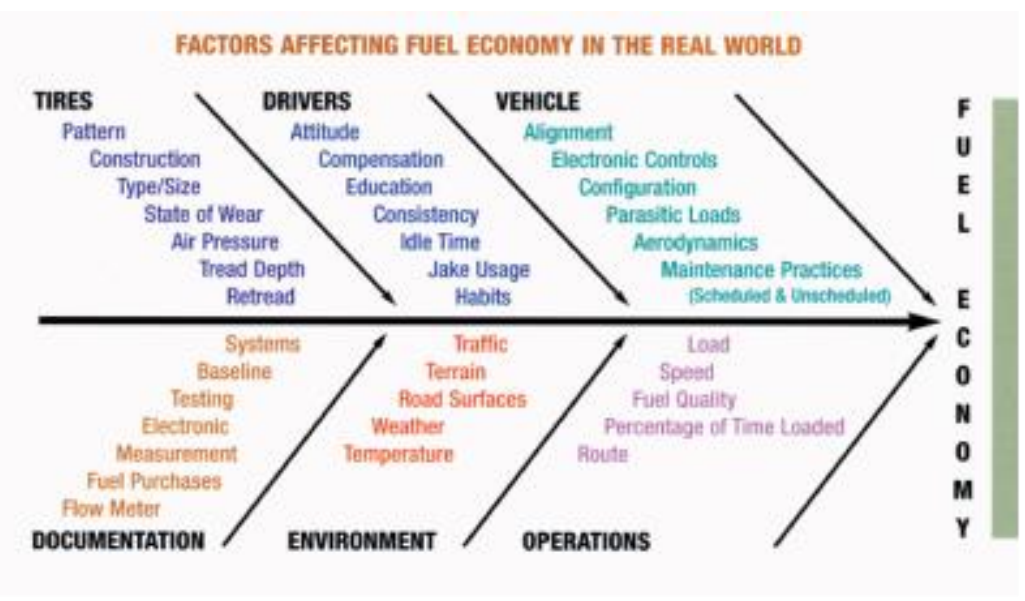

Figure 1 Factors affecting fuel economy in the real world [2] and [3]

The interaction between the wheel and the medium on which a vehicle operates is the main factor to find the optimum performance from an off-road vehicle, as seen in Figure 2. The problem of wheel-soil interaction may seem antiqued in this technological advanced age of space exploration, computers, microelectronics and robotics. It is, nevertheless, a complex problem, at least from an analytical viewpoint, for the characteristics of wheel-soil interaction is influenced by a large number of factors [4].

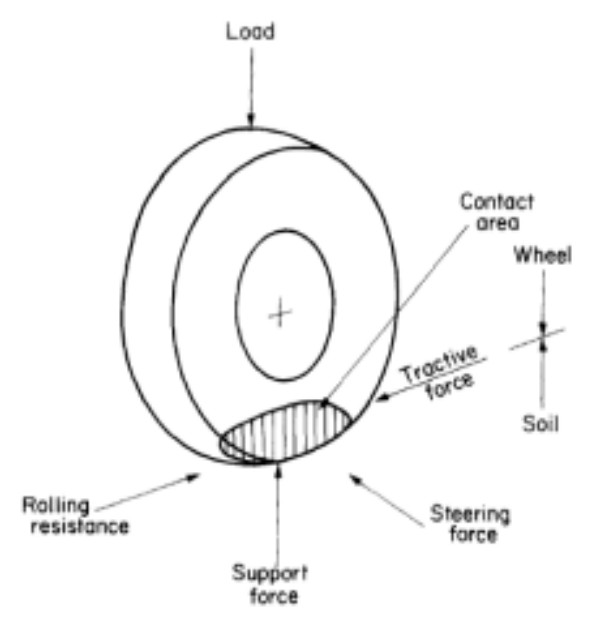

Figure 2 Forces acting on a rolling tyre in soil [4]

Now most of the new military tactical vehicles produced in the United States are equipped with Central Tyre Inflation System (CTIS) where this system is used to adjust the tire pressure to the optimum footprint on any terrain. In addition, the CTIS reduces downtimes associated with tire malfunctions, such as minor punctures, leaks, or immobilization in muddy terrain. Therefore, the most of wheeled armoured vehicles are equipped with a CTIS Tyres for help during emergency conditions [5]. The CTIS allows the 
tyres to dynamically change to lower inflation pressures to accommodate speed in rough terrain. The reduced pressure allows the tyre to be more compliant, thereby maintaining better ground contact, as well as giving the operator a more comfortable ride. In agriculture, CTIS has been a subject of discussion for some time, as mentioned by Hassan [6-7].

Forrest et al [8] stated that some of the enabling factors for central tyre inflation were advances in tyre technology. Early research using radial tyres consistently showed an increase in tractive performance. If the inflation pressure was reduced, the footprint of the tyre became larger and distributed the load over a larger area, helping to reduce the motion resistance in soft soils. Also, if the inflation pressure was reduced, the stiffness of the tyres was reduced. The softer tyres maintained better ride quality by flexing to accommodate for unevenness in the terrain. The $50 \%$ reduction in minimum inflation pressure given by the new inflation tables for radial ply tyres increased the vehicle performance when using CTIS, making the economic aspects of central tyre inflation even more appealing.

Schlechter [9] represented briefly the influence of tyre pressure reduction on the mobility of wheeled vehicles on the basis of measurement and calculation results. Significant characteristics and the differences of various central tyre inflation systems installed in series production vehicles and prototypes are demonstrated. Deflation and inflation times of regulation devices serve as performance characteristics for a systematic comparison. Reduction of the tyre pressure helps to increase the transferable traction force, due to the enlargement of the tyre tread area, an enlargement of the effective tyre diameter and thus a reduction of rolling resistance. A tyre pressure reduction from 3.5 bar to 2.0 bar resulted almost in a duplication of the traction force. A tyre pressure of 4.3 bar may possibly permit a vehicle to travel only $65 \%$ of a selected and measured terrain. If the tyre pressure is reduced to 1.3 bar the same vehicle may travel approximately a $90 \%$ of the same terrain under the same marginal conditions, as shown in Figure 3. The Ref. [9] supports our idea in this paper where it shows the effect of the tyre pressure on the traction force, which affects the vehicle speed and draw bar pull in the end.

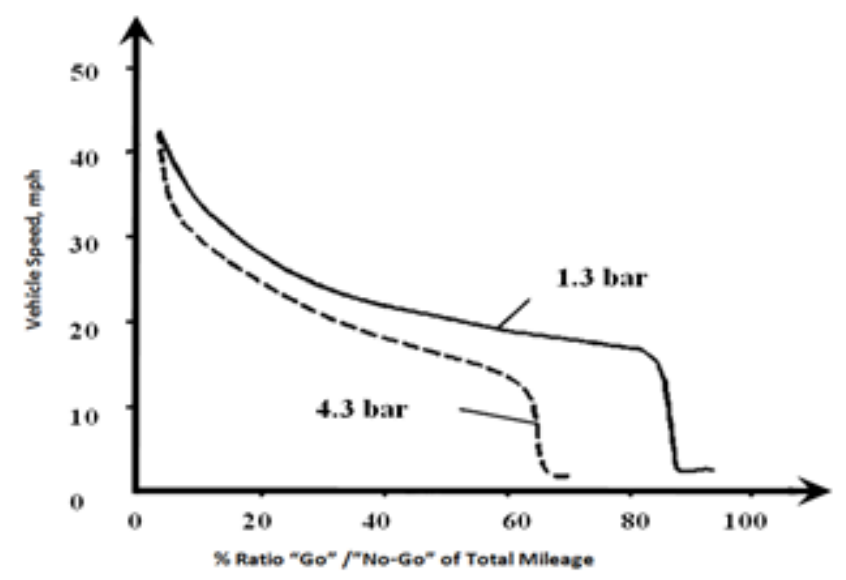

Figure 3 Effect of reduced tyre inflation pressure on the ratio of "Go /No-Go" function of vehicle speed [9] 


\section{MATERIALS AND METHODS}

In this section describe the influence tyre inflation pressure on the contact area; also define the traction efficiency, and found the relationships between tyre-soil interactions.

\subsection{Effect of the tyre inflation pressure on the contact area}

The tyre dimensions and ground pressures can be changed by controlling the inflation pressure as shown in Fig. 4. Internal air pressure in the tyre directly contributes to the tyre stiffness and controls the contact area and both of them influence the traction capability of the tyre. In general, for better traction on soft loose soil, a decrease in the inflation pressure results in an improvement of normal and tangential interfacial stresses and accordingly in the traction performance of the tyre [11].

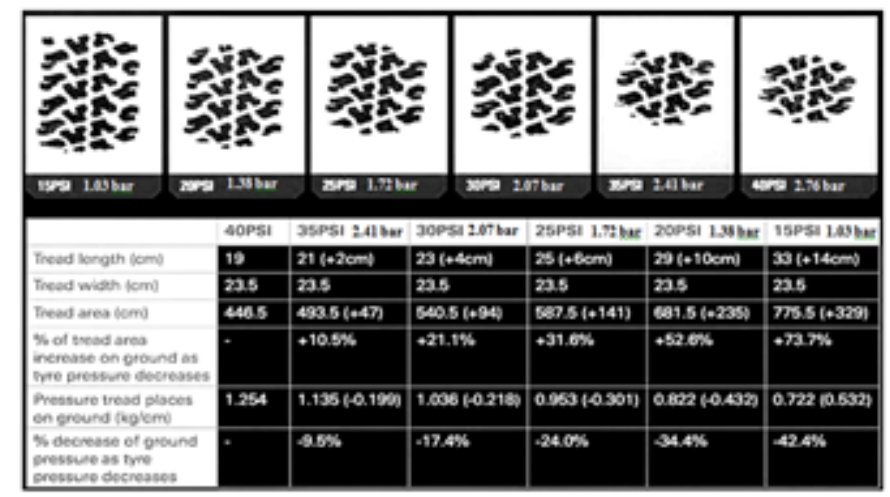

Figure 4 Effect of inflation pressure on the dimensions and ground pressure [10]

Figure 5 shows contour a set of maps of pressure distribution under 11.0-38 smooth tyre on firm sand at three inflation pressures $0.97,0.69$ and 0.41 bar [12].

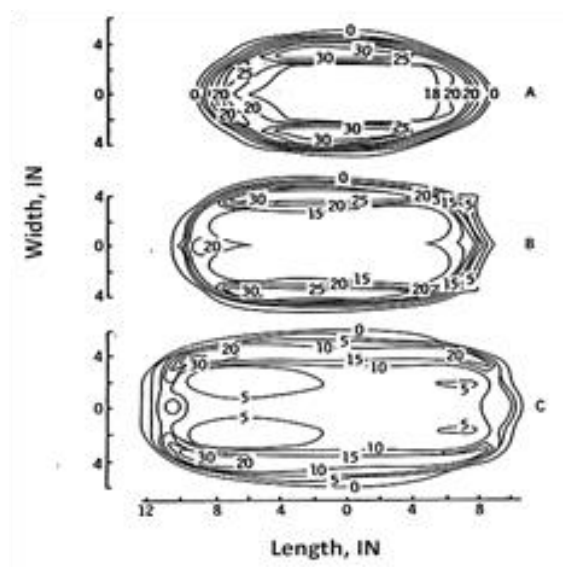

Figure 5 Contour maps of pressure distribution under a 11.0-38 smooth tyre on firm sand at different inflation pressures 0.97, 0.69 and 0.41 bar, [12] 


\subsection{Load Capacity}

The vertical load carrying capability of off-road tyres is mainly determined on the basis of the volume and pressure of the air that they contain. Thus, vertical load capacity increases with tyre size and inflation pressure. Figure 6 shows how soil pressure varies with depth for tyres of different sizes and carrying different vertical loads, but all operating at the same inflation pressure. The pressure contours extend deeper into the soil profile with increased vertical load even though the surface pressures are similar. This effect is the basis for the rule of thumb that surface soil compaction is related to the inflation pressure while subsoil compaction is related to the total vertical load on the axle.

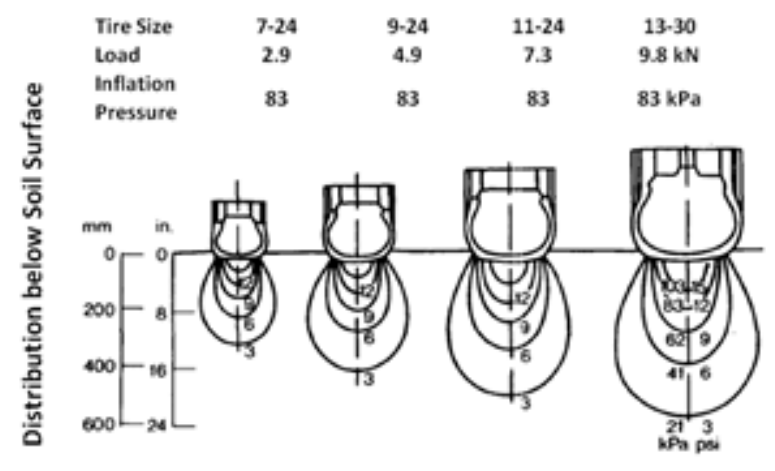

Figure 6 Distribution of major principal stresses in a soil under various tyre loads [13]

\subsection{Traction Efficiency}

To characterize the efficiency of an off-road vehicle in transforming the engine power to the power available at the drawbar, the traction efficiency is often used. It is defined as the ratio of the drawbar power $P_{d}$ to the corresponding power delivered by the engine power $P$ [13]. Improving traction efficiency, reduces costs through improved fuel efficiency and increases the productivity of off road vehicle that means providing the immediate fuel savings and improved performance. Figure 7 shows maximum power is available at the peak of each curve - a compromise between rolling resistance and wheel slip [14-15]. 


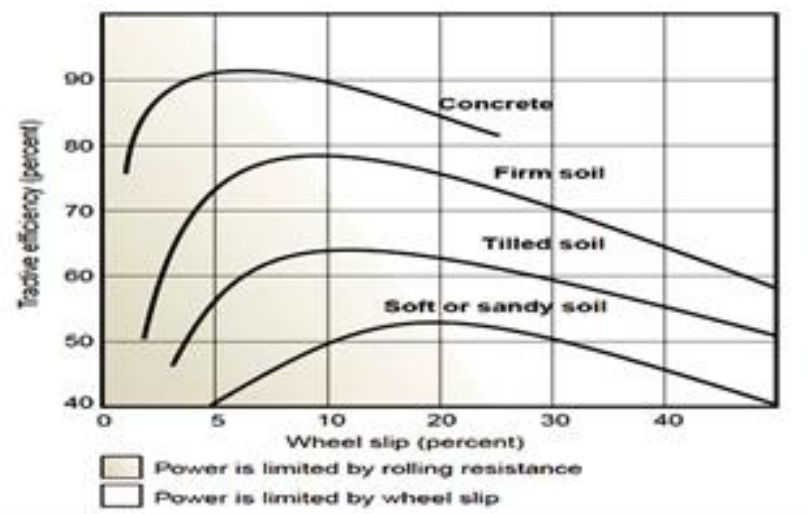

Figure 7 Maximum power is available at the peak of each curve - a compromise between rolling resistance and wheel slip [14-15]

The traction Efficiency $\eta_{d}$ is defined as:

$\eta_{d}=P_{d} / P=F_{d} \cdot V_{a} / P$

Where:

$F_{d}$ - drawbar pull or force available at the drawbar $=F-T F$

$\mathrm{V}_{\mathrm{a}}$ - actual speed of motion

$\mathrm{F}$ - thrust force

$\mathrm{TF}$ - towing or rolling resistance force.

Traction Efficiency is a product of three terms related to; efficiency of motion $\eta_{m}$, slip efficiency $\eta_{s}$, and the transmission $\eta_{t}[13]$.

$\eta_{d}=\eta_{m} \cdot \eta_{s} \cdot \eta_{t}$

This can be easily proved by substituting the input power $P$ in equation (1) by the thrust force $F$ multiplied by the theoretical speed $V_{t}$ and divided by the transmission efficiency $\eta_{t}$, and the actual speed $V_{a}=V_{t}(1-s)$ :

$$
\begin{aligned}
\eta_{d}=F_{d} & \cdot V_{a} / P=F_{d} \cdot V_{t}(1-s) / F \cdot V_{t} / \eta_{t} \\
& =\left(F_{d} / F\right)(1-s) \eta_{t} \\
& =\eta_{m} \cdot \eta_{s} \cdot \eta_{t}
\end{aligned}
$$

Where:

$$
\begin{aligned}
& \eta_{m}=F_{d} / F \\
& \eta_{s}=1-s
\end{aligned}
$$

The efficiency of slip characterizes the power losses, and also the reduction in vehicle speed. Since slip increases with an increase of tractive effort and drawbar pull, the efficiency of slip decreases as the drawbar pull increases.

As can be seen from Eq. 3, the traction efficiency is the product of the efficiency of transmission, efficiency of motion, and efficiency of slip. In general, it exhibits a peak at an 
intermediate value of drawbar pull, as shown in Fig. 8. To increase the traction efficiency, optimization of the form and size of the vehicle running gear is of importance [13].

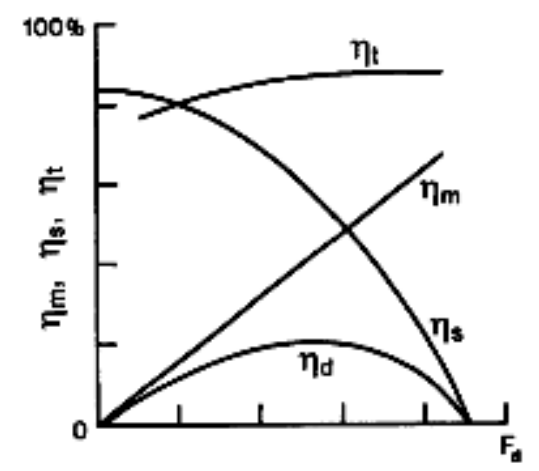

Figure 8 The variations of traction efficiency with Drawbar pull [13]

The longitudinal slip of the vehicle running gear, when a driving torque is applied, is usually defined by:

$S=\left(1-\frac{V_{a}}{\omega . r}\right) \cdot 100 \%=\left(1-\frac{r_{e}}{r}\right) \cdot 100 \%$

Where

$s$ - the longitudinal slip

$V_{a}$ - the actual vehicle speed

$\omega$ - the angular speed of the tyre

$r$ - the rolling radius of the free-rolling tyre and

$r_{e}$ - the effective rolling radius of the tyre.

\subsection{Tyre-Soil Interaction}

There must be some slip between the tyre and the soil surface for an efficient operation. Limited slip improves traction efficiency, which is the ratio of drawbar power to axle power and also provides a safety cushion against shock overloads that could damage the power-train; some wheel slippage is needed to reduce wear on the power train.

Figures 9 and 10 present the effects of wheel slip on sinkage and the tyre equivalent sinkage values as a function of the slip ratios. It can be seen that the equivalent tyre sinkage values are rising with the increase of the slip ratio and the trend becomes steeper when the slip ratio is larger [16-18]. 




Figure 9 Sinkage versus slip for a grooved tyre [16-17]

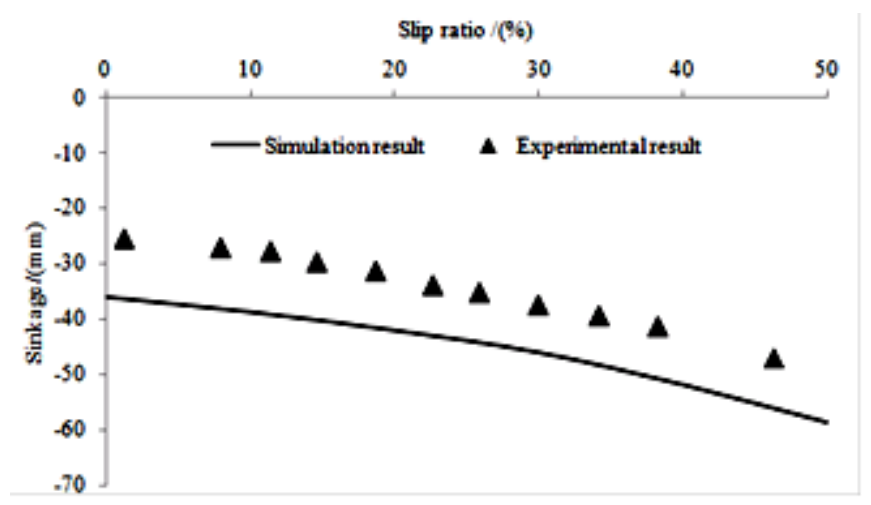

Figure 10 The relation between tyre sinkage and slip ratio [18]

Figure 11 illustrates the equivalent values (the average drawbar pull value under each slip ratio) of the drawbar pull as a function of the slip ratios. It can be seen that the drawbar pull shows an increasing trend when the slip ratio is less than $25 \%$, and its value tends to be stable when the slip ratio is larger than $25 \%$ [18]. 


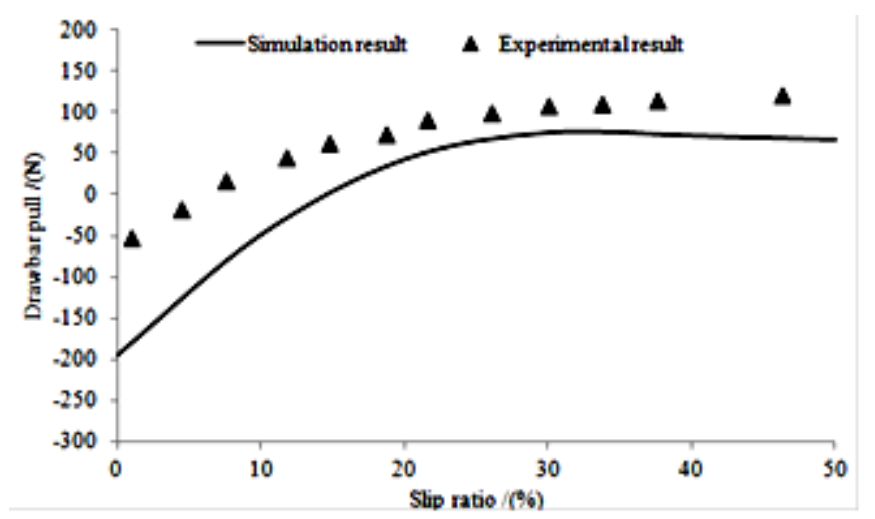

Figure 11 The relation between tyre drawbar pull and slip ratio [18]

As can be seen from Figs. 9 to 11, the tyre slip ratio has a strong effect on its running behaviour. The sinkage value of the tyre rises with the increases of the slip ratio due to the tyre digging effect. This leads to the increase of the bulldozing resistance which is the main resistance for tyre running on sand soil. The drawbar pull shows a steeper increasing trend when the slip ratio is less than $25 \%$ and the values tend to be stable when the slip ratio is larger due to the dramatic increase of the resistance under these slip ratio conditions. Floatation is defined as the ability of a vehicle to travel without excessive sinkage [11]. As sinkage increases, the drag forces become excessively large, and the vehicle will be immobilized. The higher the ground pressure generated by a loaded tyre moving on a soft soil the lesser will be its flotation as it will more sink in the soil, especially when its value is higher than the limit bearing capacity of the soil. Fig. 12 shows a schematic representation of the relationships of tyre stiffness, soil strength, and the resulting degree of tyre flotation [19].

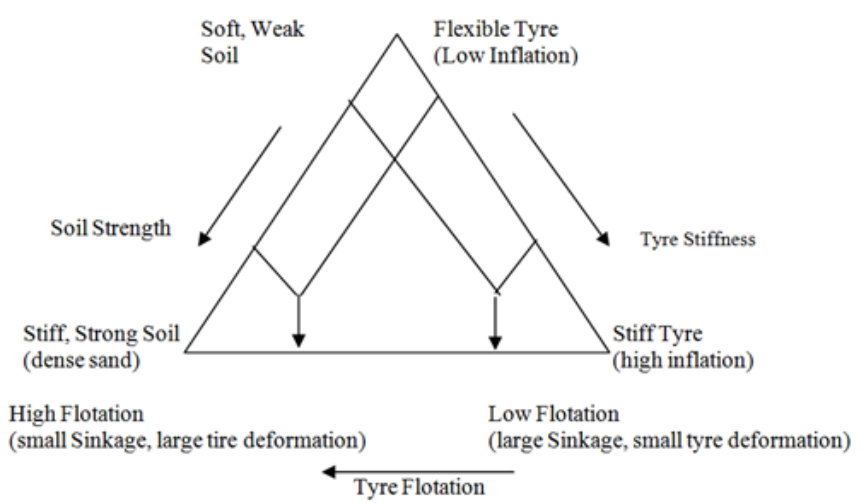

Figure 12 Tyre flotation diagram [19] 
To get good tyre flotation when moving on soft soils like dry loose sands, the stresses generated by tyre loading should not overpass the limit bearing capacity of the soil. Fig. 13 shows, the point of transition from a relatively high to a much lower resistance to penetration on the curve relating the pressure under a loaded plate and the plate sinkage [19].

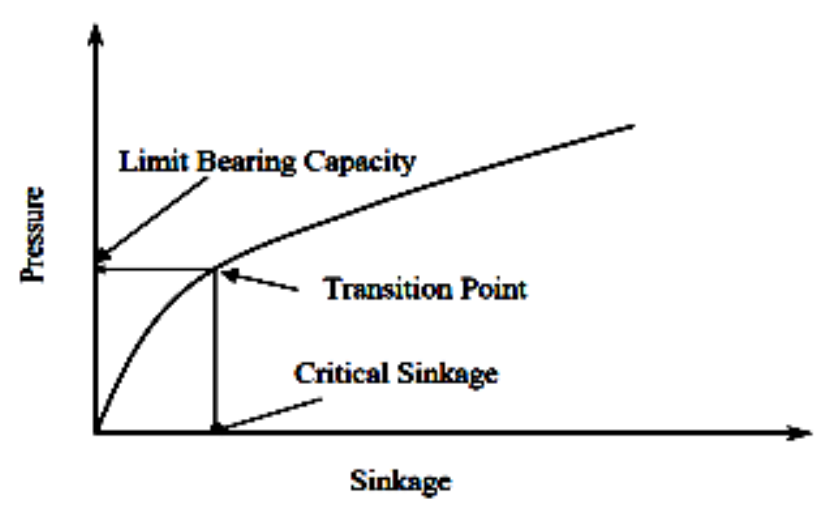

Figure 13 Limit bearing capacity of dry loose sand, [19]

Figure 14 shows the relationship between Effective contact area vs. tyre pressure at different tyre load for the same tyre and soil, whereas the effective contact area is revising proportional to the tyre inflation pressure.

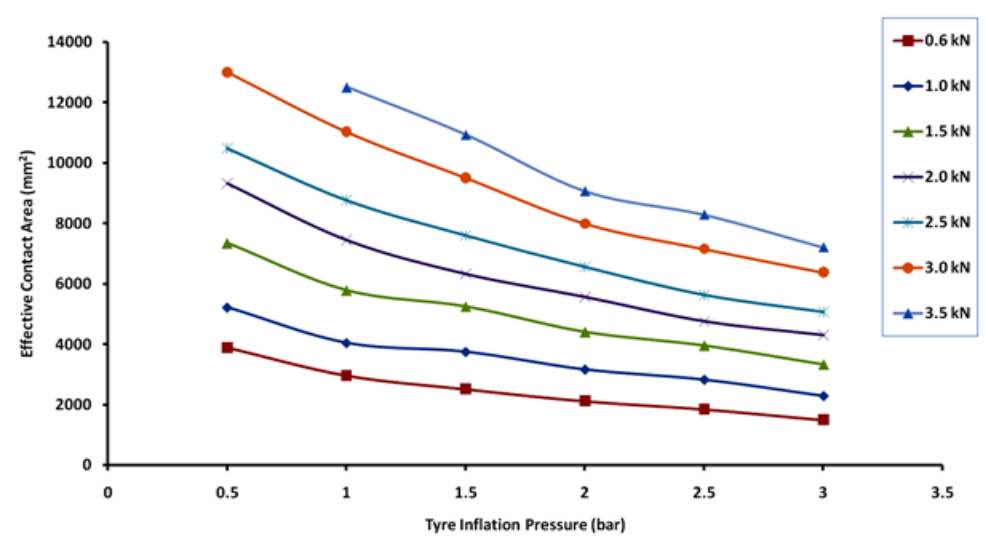

Figure 14 Effective contact area vs. tyre pressure at different tyre load [20]

From all of the previous figures it can be said that excessive tyre slip causes loss of power and accordingly excessive fuel consumption. On the other hand, when controlling the tyre slip by reducing the inflation pressure the tyre slip efficiency and accordingly its traction efficiency increases. 


\section{A NEW EMPIRICAL FORMULA}

A trial to correlate empirical the measured results (collected data [21]) for slip and inflation pressure of tyre size 10.00-28 and drawbar pull has been done on loose sand. The software (Data Fit, version 6.1.10) was used to establish an empirical formula by correlating these values [22]. The new empirical formula that can be used to determine the drawbar pull of off road vehicles depend on two parameters, slip and inflation pressure and is written as:

$$
\begin{aligned}
& \mathrm{F}_{\mathrm{d}}=20.1+34.23 \mathrm{~S}-1.786 \mathrm{~S}^{2}+0.052 \mathrm{~S}^{3}-0.0008 \mathrm{~S}^{4}+4.66 \mathrm{~S}^{5}-\left(286.3 / \mathrm{P}_{\mathrm{i}}\right) \\
& +\left(292.74 / \mathrm{P}_{\mathrm{i}}^{2}\right)-\left(93.63 / \mathrm{P}_{\mathrm{i}}^{3}\right)+\left(9.42 / \mathrm{P}_{\mathrm{i}}^{4}\right)
\end{aligned}
$$

Where:

$\mathrm{F}_{\mathrm{d}}$ - Drawbar pull, kg

S - Slip, \%

$\mathrm{Pi}$ - Inflation Pressure, bar.

Figure 15 shows the influence of tyre inflation on the Drawbar pull at five pressures; $0.2,0.4,0.6, .0 .8,1.0$ bar. As the figure shows, the gain in the drawbar pull force is much higher at low values of travel reduction (wheel slip), and that this gain is also much higher at very low pressures $(0.2,0.4$ bar). A good accuracy has been achieved between the actual and the predicted values based on the above empirical formula for Drawbar pull.

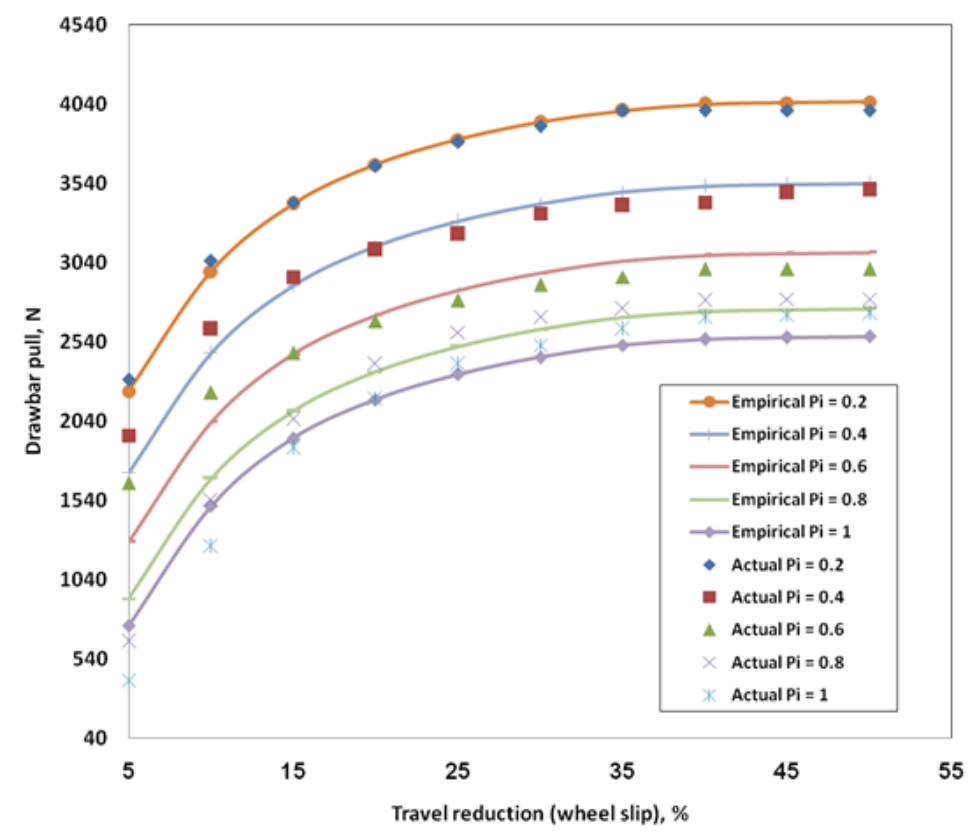

Figure 15 the influence of tyre inflation pressure on the drawbar pull 
In this paper, we use Data Fit software version 6.1.10 to make sure from the results of the empirical formula and results of the program are shown in Table (1) and the Fig. 16 shows from the residual normal probability plot that the error terms are normal distribution.



Figure 16 Residual Normal probability plot

Table 1 The statistical results of Data Fit Software

\begin{tabular}{|l|}
\hline DataFit version 6.1 .10 \\
\hline Equation ID: $\mathrm{a}+\mathrm{b}^{*} \mathrm{x} 1+\mathrm{c}^{*} \mathrm{x} 1^{\wedge} 2+\mathrm{d}^{*} \mathrm{x} 1^{\wedge} 3+\mathrm{e}^{*} \mathrm{x} 1^{\wedge} 4+\mathrm{f}^{*} \mathrm{x} 1^{\wedge} 5+\mathrm{g} / \mathrm{x} 2+\mathrm{h} / \mathrm{x} 2^{\wedge} 2+\mathrm{i} / \mathrm{x} 2^{\wedge} 3+\mathrm{j} / \mathrm{x} 2^{\wedge} 4$ \\
\hline Number of observations $=49$ \\
\hline Number of missing observations $=1$ \\
\hline Solver type: Nonlinear \\
\hline Nonlinear iteration limit $=250$ \\
\hline Diverging nonlinear iteration limit $=10$ \\
\hline Number of nonlinear iterations performed $=9$ \\
\hline Residual tolerance $=0.0000000001$ \\
\hline Sum of Residuals $=-1.12030562604559 \mathrm{E}-08$ \\
\hline Average Residual $=-2.28633801233794 \mathrm{E}-10$ \\
\hline Residual Sum of Squares $($ Absolute $)=7476.85373157776$ \\
\hline Residual Sum of Squares (Relative) $=7476.85373157776$ \\
\hline Standard Error of the Estimate $=13.8460896373519$ \\
\hline Coefficient of Multiple Determination $\left(\mathrm{R}^{\wedge} 2\right)=0.9757194749$ \\
\hline Proportion of Variance Explained $=97.57194749 \%$ \\
\hline Adjusted coefficient of multiple determination $($ Ra^2) $=0.9701162768$ \\
\hline Durbin-Watson statistic $=0.863124596313696$ \\
\hline Regression Variable Results \\
\hline Variable $\quad$ Standard Error \\
\hline
\end{tabular}




\begin{tabular}{|c|c|c|c|c|}
\hline $\mathrm{a}$ & 20.05459 & 239.6898 & 0.083669 & 0.93375 \\
\hline $\mathrm{b}$ & 34.23221 & 11.70312 & 2.925049 & 0.00571 \\
\hline $\mathrm{c}$ & -1.78571 & 1.16031 & -1.539 & 0.13188 \\
\hline $\mathrm{d}$ & 0.051879 & 0.050336 & 1.030658 & 0.30905 \\
\hline $\mathrm{e}$ & -0.00078 & 0.000986 & -0.79035 & 0.4341 \\
\hline $\mathrm{f}$ & $4.66 \mathrm{E}-06$ & $7.14 \mathrm{E}-06$ & 0.652603 & 0.51784 \\
\hline $\mathrm{g}$ & -286.394 & 516.8445 & -0.55412 & 0.58266 \\
\hline $\mathrm{h}$ & 292.7395 & 387.7003 & 0.755066 & 0.45475 \\
\hline $\mathrm{i}$ & -93.6314 & 116.4156 & -0.80429 & 0.42611 \\
\hline $\mathrm{j}$ & 9.417882 & 11.53432 & 0.816509 & 0.41917 \\
\hline
\end{tabular}

To better illustrate and tie all the parameters, the relationship is drawn in three dimensions as shown in Fig. 17. This graph can be used as an image in the proposed model and enables determining the appropriate tyre air pressure to obtain the maximum drawer pull.

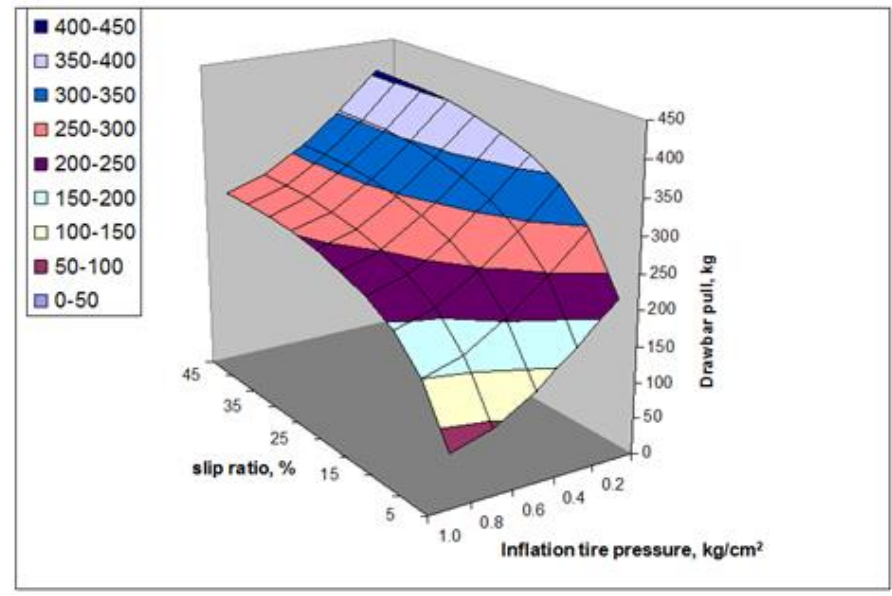

Figure 17 The Relationships of Drawbar pull, tyre inflation pressure, and slip

\section{PROPOSED MODEL}

The proposed model consists of; a control unit that receives the wheel speed sensor signals from each wheel and calculate the theoretical speed of each wheel and a radar gun sensor that measures the vehicle ground speed (actual travelling speed). By knowing the theoretical and actual vehicle speeds, the control unit can calculate the tyre wheel slip. The control unit also can determine the air pressure at each tyre by using a wireless pressure sensor for each wheel. From the stored data in the microprocessor of the control unit actuating signals will be operating the air solenoid valves to adjust the tyre pressure for obtaining the optimum drawbar pull. Figure 18 represents the layout of the proposed model and the Figure 19 shows the flowchart of the proposed model. 


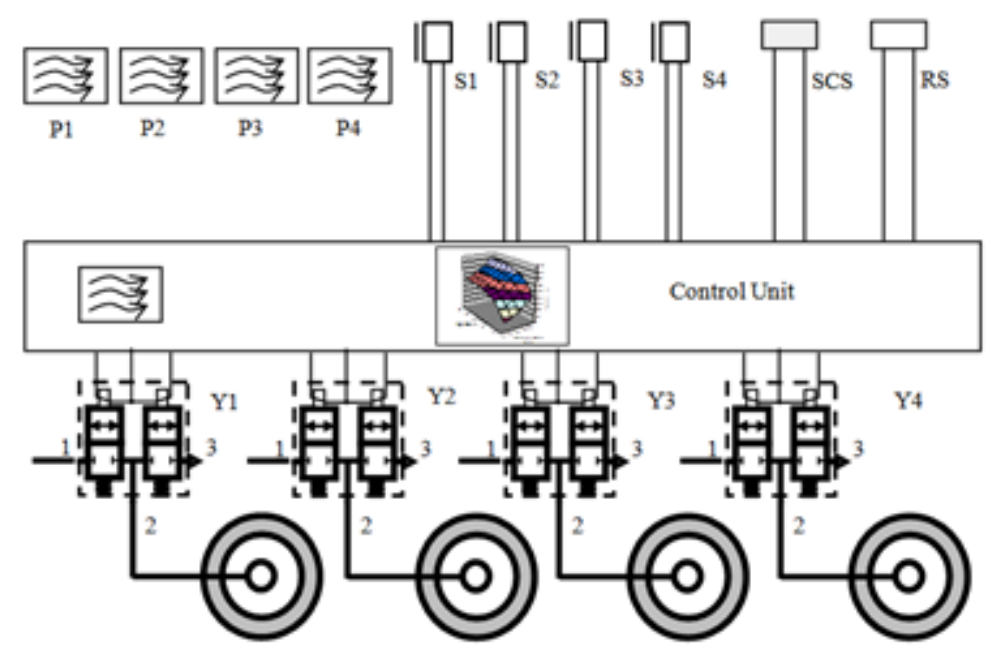

Figure 18 Layout of the proposed model for optimizing the tyre drawbar pull

\section{Where:}

P1: wheel tyre pressure wireless on front right wheel P2: wheel tyre pressure wireless on front left wheel P3: wheel tyre pressure wireless on rear right wheel P4: wheel tyre pressure wireless on rear left wheel RS: Radar gun sensor

S1: wheel speed sensor on front right wheel S2: wheel speed sensor on front left wheel
S3: wheel speed sensor on rear right wheel S4: wheel speed sensor on rear left wheel SCS: Soil Compaction or Density Sensor Y1: solenoid valve for front right wheel Y2: solenoid valve for front left wheel Y3: solenoid valve for rear right wheel Y4: solenoid valve for rear left wheel

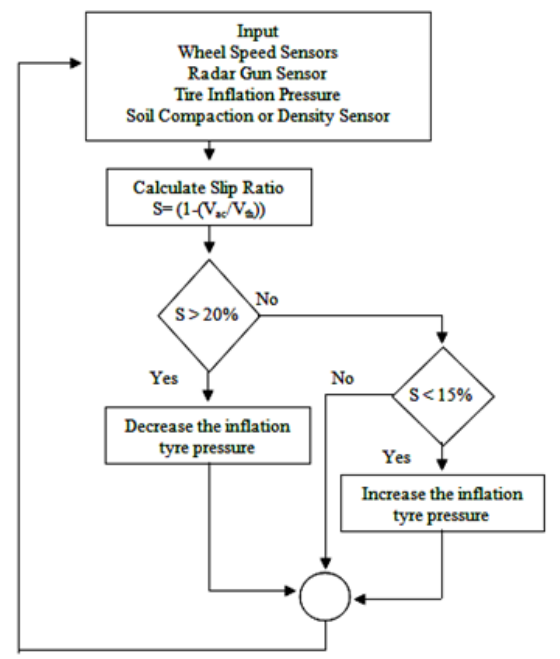

Figure 19 Flow chart of the proposed model 


\section{CONCLUSIONS}

The present work introduces a new Empirical Formula that can be used to determine the drawbar pull as a function of tyre inflation pressure and slip. The proposed model that includes a closed loop control system with various sensors and solenoid valves in addition to the processor) can be applied on real vehicles to adjust a tyre inflation pressure according to the wheel slip to obtain optimum off-road vehicles` drawer pull and traction efficiency. Finally the tyre pressure control by sensing slip ratio, this reduces the tyre sinkage on the soil and thus reduces the rolling resistance and leads to lower fuel consumption, and also keeps the tyre from rapid wear and increase lifetime.

\section{REFERENCES}

[1] J. C. Brendan, "Development of an Off-Road Capable Tyre Model for Vehicle Dynamics Simulations," Ph.D. Thesis, Blacksburg, Virginia, 2008.

[2] SINGH, "Tyres \& Truck Fuel Economy", Special Edition Four, Bridgestone Firestone, 2008.

[3] S. Farkas, "Fuel Efficiency in Truck Industry" Scientific Bulletin of the "Petru Maior" University of Tîrgu Mureş, Vol. 7 (XXIV), no. 2, 2010.

[4] W. C. Plackett, "A Review of Force Prediction Methods for Off-Road Wheel," Journal of Agricultural Engineering Research, Vol. 31, Pages 1-29, 1985.

[5] G. H. Hohl, "Military Terrain Vehicles," Journal of Terramechanics, Vol. 44, Pages 23-44, 2007.

[6] R. W. Kaczmarek, "Central Tyre Inflation Systems (CTIS) - A Means to Enhance Vehicle Mobility," Proceeding of the 8th International Conference of the ISTVS, England, Cambridge, 1984.

[7] E. Hassan, "A Prime Mover Equipped with Central Tyre Inflation System," ASAE, Paper No. 83-1055, Michigan, 1983.

[8] P. J. Forrest, I.F. Reed and G.V Constantakis "Tractive Characteristics of Radial-Ply Tyres," Transation of ASAE, Vol. 4 (11), Pages 108-115, 1962.

[9] H. P. Schlechter, "Design and Performance of Central Tyre Inflation Systems," Proceeding of the 8th International Conference of the ISTVS, Vol. I, Pages 295-320, Austria, 1984.

[10] http://www.xterranation.org/showthread.php?5849-Tips-for-Offroading-on-Sand, 2014.

[11] R. N. Yong, , A. F. Ezzat and S. Nicolas, "Vehicle Traction Mechanics," ISBN 0-44442378-8 (vol. 3), ISBN 0-444-41940-3 (Series), Elsevier Science Publishers B. V., 1984.

[12] L. K. Leslie, and A. N. Edward, "Soil Mechanics for Off-Road Vehicle Engineering," ISBN 0-87849-020-5, First Edition, Trans Tech Publications, Printed in Germany, 1978.

[13] J. Y. Wong, Theory of Ground Vehicle, Third Edition, John Wiley \& Sons, Inc, 2001.

[14] W. C. William, "Tractor Tyre and Ballast Management," Dept. of Agricultural Engineering, G1235, Univ. of Missouri Extension, August 1997.

[15] "Tractor Tyre and Ballast Management", http://extension.missouri.edu/publications/DisplayPub.aspx?P=G1235, August 1997.

[16] S. Hisanori, N. Hiroshi, T. Yuzuru, K. Takahiro, M. Hisao, S. Hiroshi, M. Juro and O. Katsuaki, "Experimental Analysis of Tread Pattern Effects on Tyre Tractive Performance on Sand using an Indoor Traction Measurement System with Forced-slip 
Mechanism," Engineering in Agriculture, Environment and Food, Volume 3, Issue 2, 2010, Pages 61-66.

[17] S. Hisanori, N. Hiroshi, T. Yuzuru, K. Takahiro, M. Hisao, S. Hiroshi, M. Juro and O. Katsuaki, "FE-DEM Analysis of the Effects Tread Pattern on Tractive Performance of Tyres Operating on Sand," Journal of Mechanical Systems for Transportation and Logistics, Volume 2, No 1, 2009.

[18] C.L. Zhao and M.Y. Zang, "Alternately Moving Road Method for the FEM/DEM Simulation of Tyre-Sand Interactions," ICCM, Cambridge, England, 28-30th July 2014.

[19] S. Shaaban, "Tyre Flotation on Sandy Soils," Al-Azhar Engineering Sixth, International Conference, Sept. 1-4, 2000.

[20] M. E. Haytham, "Use of Adaptive Tyre Pressure Control for Enhancing Vehicle Performance," Ph.D. Thesis, Helwan University, Egypt, 2010.

[21] J. Zombori, "Drawbar Pull Tests of Various Traction Devices on Sandy Soils," Journal of Terramechanics, Vol. 4, No. 1, pp. 9-17, 1967.

[22] “Oakdale Engineering”, http://www.curvefitting.com, 2008. 